\title{
Gear Modifications for Fishing Octopus, Octopus vulgaris, on Live-bottom and Adjacent Flat Bottom Habitats in Coastal Waters off North Carolina
}

\author{
PAUL J. RUDERSHAUSEN
}

\section{Introduction}

The Common Octopus, Octopus vulgaris, is found worldwide, including over the continental shelf in the U.S. South Atlantic Bight (Voss et al., 1973). While it is not targeted off North Carolina, the octopus is a high-value species that is often taken as bycatch in wire mesh traps set for Black Sea Bass, Centropristis striata. Ex-vessel and wholesale (2012) prices for octopus are approximately $\$ 3.30$ and $\$ 8.80$ per $\mathrm{kg}$, respectively (C. J. Renda, Beaufort, N.C., personal commun.). Relatively high prices for octopi (compared to the majority of inshore and offshore finfish species landed in the U.S. South Atlantic) have prompted commercial fishermen to consider the feasibility of developing small-scale fishing operations for this

Paul J. Rudershausen is with the North Carolina State University Department of Biology, Center for Marine Science and Technology, 303 College Circle, Morehead City, NC 28557 (email:pjruders@ncsu.edu).

doi: dx.doi.org/10.7755/MFR.75.3.2 species. No known fishermen in Onslow Bay, N.C., target octopi.

Octopi interest commercial fishermen for several reasons in addition to their relatively high market value. Annual catch quotas and seasonal spawning closures used to manage commercially exploited finfishes in the U.S. South Atlantic limit the number of species that ocean fishermen can target at certain times of the year. This is especially true in the snapper-grouper reef fish complex, as octopi are found in habitats similar to many commercially exploitable reef fishes. Some offshore commercial operators that target reef fish in the U.S. South Atlantic have been actively seeking other species to target as regulations have been updated for compliance with the Magnuson-Stevens Fishery Conservation Act.

Gear set for octopi is relatively inexpensive and easy to deploy. Octopus pots are often made of plastic or clay (Rathjen, 1991) or PVC pipe (Whitaker et al., 1991). Octopus traps can be also be made from scrap conduit. Octopi enter pots as a habitat alternative to natural creviced structure, so pots require no bait; this is a further costsaving consideration in targeting this species.

A directed fishery for octopi in the U.S. South Atlantic would have low bycatch rates. Because octopus pots must remain open in order to catch this species, "ghost" fishing by lost gear is essentially eliminated, and animals entering pots are continually free to leave at will.

Emperical data is lacking on pot soak times, bottom types, and water temperatures (seasons) favorable for catching octopi in continental shelf waters off North Carolina. The relationship between octopus catches off South Carolina and gear type, fishing technique, and environmental factors were examined by Whitaker et al. (1991). Given the relatively long time span since the Whitaker et al. (1991) study, potential changes in the abundance of this species, geographic and environmental differences that could influence catch rates, and the logistics of fishing operations (how far offshore fishermen need to travel to
ABSTRACT-The Common Octopus, Octopus vulgaris, is an r-selected mollusk found off the coast of North Carolina that interests commercial fishermen because of its market value and the cost-effectiveness of unbaited pots that can catch it. This study sought to: 1) determine those gear and environmental factors that influenced catch rates of octopi, and 2) evaluate the feasibility of small-scale commercial operations for this species. Pots were fished from August 2010 through September 2011 set in strings over hard and sandy bottom in waters from 18 to 30 m deep in Onslow Bay, N.C. Three pot types were fished in each string; octopus pots with-and without lids, and conch pots.
Proportional catch was modeled as a function of gear design and environmental factors (location, soak time, bottom type, and sea surface water temperature) using binomially distributed generalized linear models (GLM's); parsimony of each GLM was assessed with Akaike Information Criteria (AIC). A total of 229 octopi were caught throughout the study. Pots with lids, pots without lids, and conch pots caught an average of $0.15,0.17$, and 0.11 octopi, respectively, with high variability in catch rates for each pot type. The GLM that best fit the data described proportional catch as a function of sea surface temperature, soak time, and station; greatest proportional catches oc- curred over short soak times, warmest temperatures, and less well known reef areas. Due to operating expenses (fuel, crew time, and maintenance), low catch rates of octopi, and high gear loss, a directed fishery for this species is not economically feasible at the catch rates found in this study. The model fitting to determine factors most influential on catch rates should help fishermen determine seasons and gear soak times that are likely to maximize catch rates. Potting for octopi may be commercially practical as a supplemental activity when targeting demersal fish species that are found in similar habitats and depth ranges in coastal waters off North Carolina. 


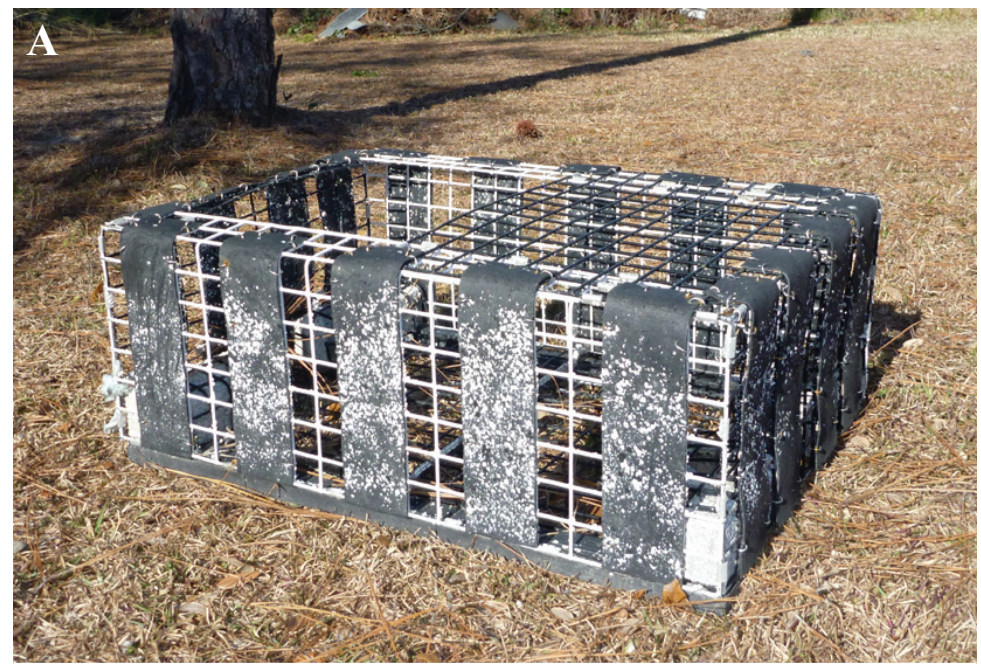

Figure 1.-A) Conch pot that was set at each end of each string of experimental pots set for octopi. B) Octopus pots with lid (left) and without lid (right) made from $10 \mathrm{~cm}$ diameter corrugated plastic drain pipe.

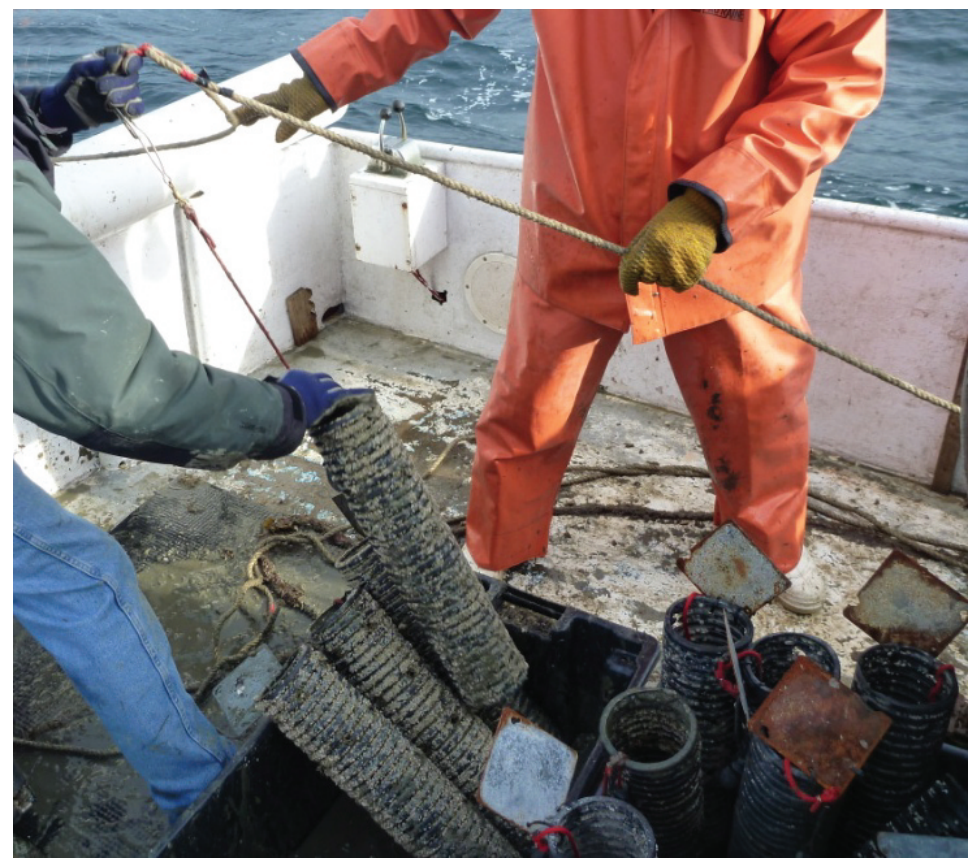

Figure 2.-Fishermen deploying a string of octopus pots. Individual pots are reaffixed to the string (warp line) as it is being set. A snood line connects each pot to the main line of the string via longline clips affixed at the mainline and at the top of each octopus and conch pot.

catch octopi), this study sought to determine those environmental and gear factors that affected catch rates off North Carolina. In an era of relatively high fuel prices $(\sim \$ 3.79 /$ gallon

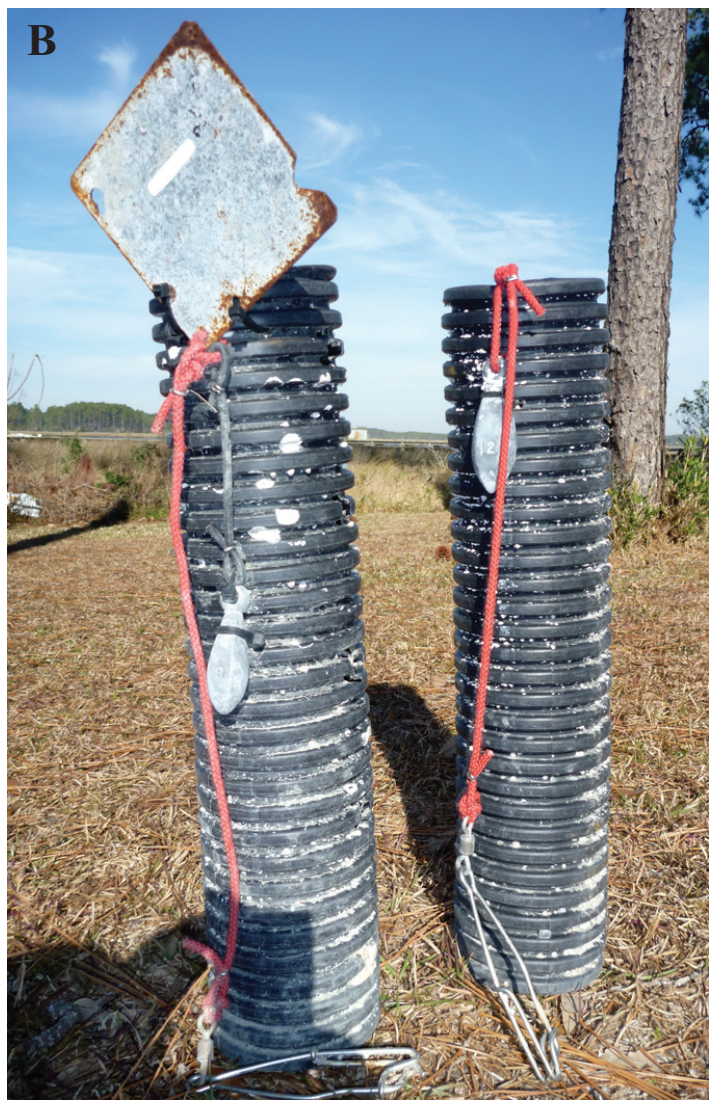

\section{Materials and Methods}

\section{Gear Design}

Three types of unbaited pots were fished in this study. The first type was conch pots that were made from vinyl-coated wire mesh $(3.8 \mathrm{~cm}$ square measure). Exterior dimensions of each conch pot were $91 \mathrm{~cm}$ long, $51 \mathrm{~cm}$ wide, and $34 \mathrm{~cm}$ high (Fig. 1a). Half of the top of each conch pot was left open to allow for egress of fish. Cement bricks $(20 \mathrm{~cm}$ wide, $10 \mathrm{~cm}$ high, and $25 \mathrm{~cm}$ long) were tied into the corners of each conch pot to help keep the string of 12 pots ( 10 octopus pots and two conch pots) weighted on the bottom. With the exception of open tops, conch pots were similar in size and construction to the typical construction of Black Sea Bass, Centropristis striata, traps that capture octopi as bycatch in the U.S. South Atlantic.

The other two pot types had a tubelike shape which has traditionally been 
used in directed fisheries (Rathjen, 1991) and studies on the biology of the octopus (Whitaker et al., 1991). Each of these octopus pots was made from a section of black plastic corrugated drain pipe $61 \mathrm{~cm}$ long and $10 \mathrm{~cm}$ wide. Several holes were drilled into each piece of pipe to permit drainage during haulback of the gear. The bottom $8 \mathrm{~cm}$ of each pot were filled with cement to keep the pot from rising off or rolling along the bottom. Two types of octopus pots were fished; those without lids and those with metal lids (Fig. 1b) that remained open while on the bottom and then closed upon haulback of the string. It was thought that lids would help reduce escapement of octopi during haulback relative to pots without lids. Each octopus pot had a $334 \mathrm{~g}$ lead fishing sinker attached to the outside near the open end to help it lay horizontally on the bottom.

Pots were fished as strings (Fig. 2) to reduce gear loss and retrieval time relative to fishing individual pots with their own standing lines. Each string had a symmetrical placement of the three pots types. The two pots at the end of each string were conch pots used as anchors in order to keep the lighter octopus pots from lifting off of or rolling on the bottom and thus elicit greater rates of occupancy by octopi. The middle ten pots of each string were octopus pots that alternately had lids and no lids. Lidded and nonlidded pots were strung in an alternating (systematic) fashion to reduce the likelihood of one pot type having a higher proportional catch rate because it was closer to preferred habitat. Octopus pots were spaced roughly $15 \mathrm{~m}$ apart.

A $1 \mathrm{~m}$ snood line connected each pot to the mainline of the string via longline clips affixed at the mainline and at the top of each octopus and conch pot. The ends of each string were marked with high fliers. The main (warp) line consisted of $0.95 \mathrm{~cm}$ polypropylenedacron rope that sank to comply with the National Oceanic and Atmospheric Administration's Marine Mammal Authorization Program guidelines. Strings were set in pairs. One string of each pair was set over flat sand bottom (no relief) and the other was set over calcareous limestone (hard) bottom with low, medium, or high relief. The study started with 10 strings. Strings lost throughout the year of field collection were not replaced.

\section{Data Collection}

Pots were fished between August 2010 and September 2011 in waters 18-30 $\mathrm{m}$ deep. Fishing occurred in the vicinity of five reef areas in Onslow Bay: Little Ten Fathom, Northwest Places, 195 Rock, 14.9 Rock, and Southeast Bottom (Fig. 3). These five areas are considered "live-bottom" sites because the porous limestone rock supports burrowing invertebrates in these locations (MacIntyre and Milliman, 1970). Only a fraction (40 or $60 \%$ ) of the ten strings was fished each day due to the transit time re-

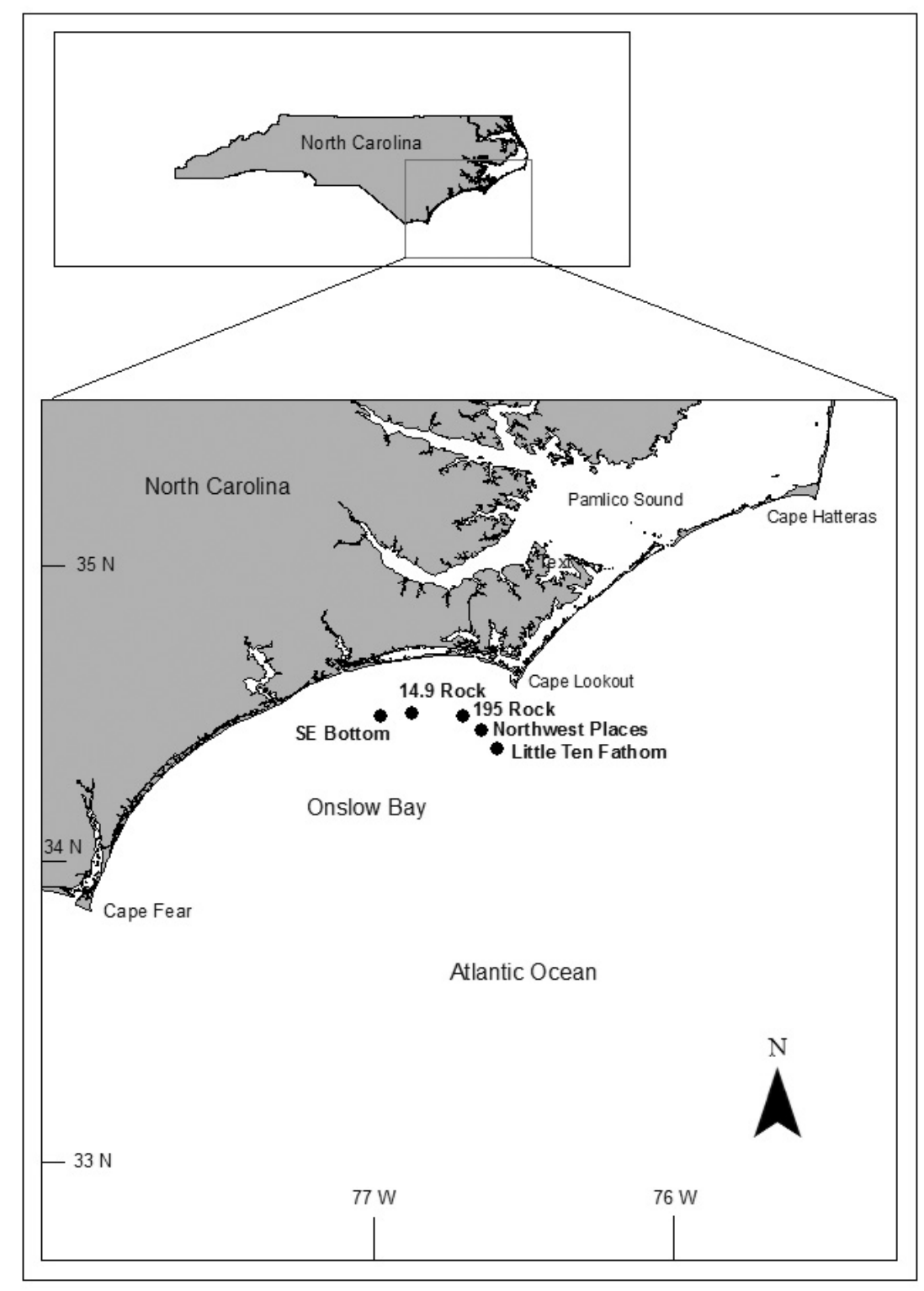

Figure 3.-Sampling sites for deployment of experimental gear used to target octopi in Onslow Bay, N.C., from August 2010 through September 2011: Little Ten Fathom, Northwest Places, 195 Rock, 14.9 Rock, and Southeast (SE) Bottom. 
quired to visit sampling sites and the sea conditions.

Strings were hauled with a hydraulic pot puller that retrieved the gear at a speed of roughly $1.2 \mathrm{~m} / \mathrm{sec}$. Strings were reset at the same stations after haulback. Crew members recorded the disposition of each pot (occupied vs. empty) and weight of each octopus $(\mathrm{kg})$. Soak times of the gear between haulback ranged from 3 to 52 days.

Bottom type and extent of vertical relief were estimated using onboard GPS and SONAR units that were monitored upon deployment of the gear. Sea surface water temperature (SST) $\left({ }^{\circ} \mathrm{C}\right)$ was recorded at a randomly selected station during each trip. SST taken during haulback of the gear was used in statistical modeling.

\section{Data Analysis}

The mean and variance of octopus catch was computed for each pot type. The relationship between octopus mass and water temperature was explored with the Pearson correlation coefficient. The relationship between occupancy of traps and soak times was examined with logistic regression to determine whether gear saturation was an issue that required data to be binned by various soak times for generalized linear modeling (see below). This logistic relationship between proportional occupancy of pots (CATCH) and soak time (TIME) (days) took the form:

$$
\begin{gathered}
\text { CATCH }=\exp \left(a+b^{*} \text { TIME }\right) / \\
\left(1+\exp \left(a+b^{*} \text { TIME }\right),\right.
\end{gathered}
$$

where $a$ and $b$ are estimated parameters of the fitted model.

After determining if gear saturation occurred, binomially distributed generalized linear models (GLM's) were fitted to the proportional catch data. These models had binomial distributions because, at most, one octopus is present in a pot set for this species. Model fitting to catch data considered multiple independent factors. SST was modeled as a continuous variable. Categorical variables considered in models included station

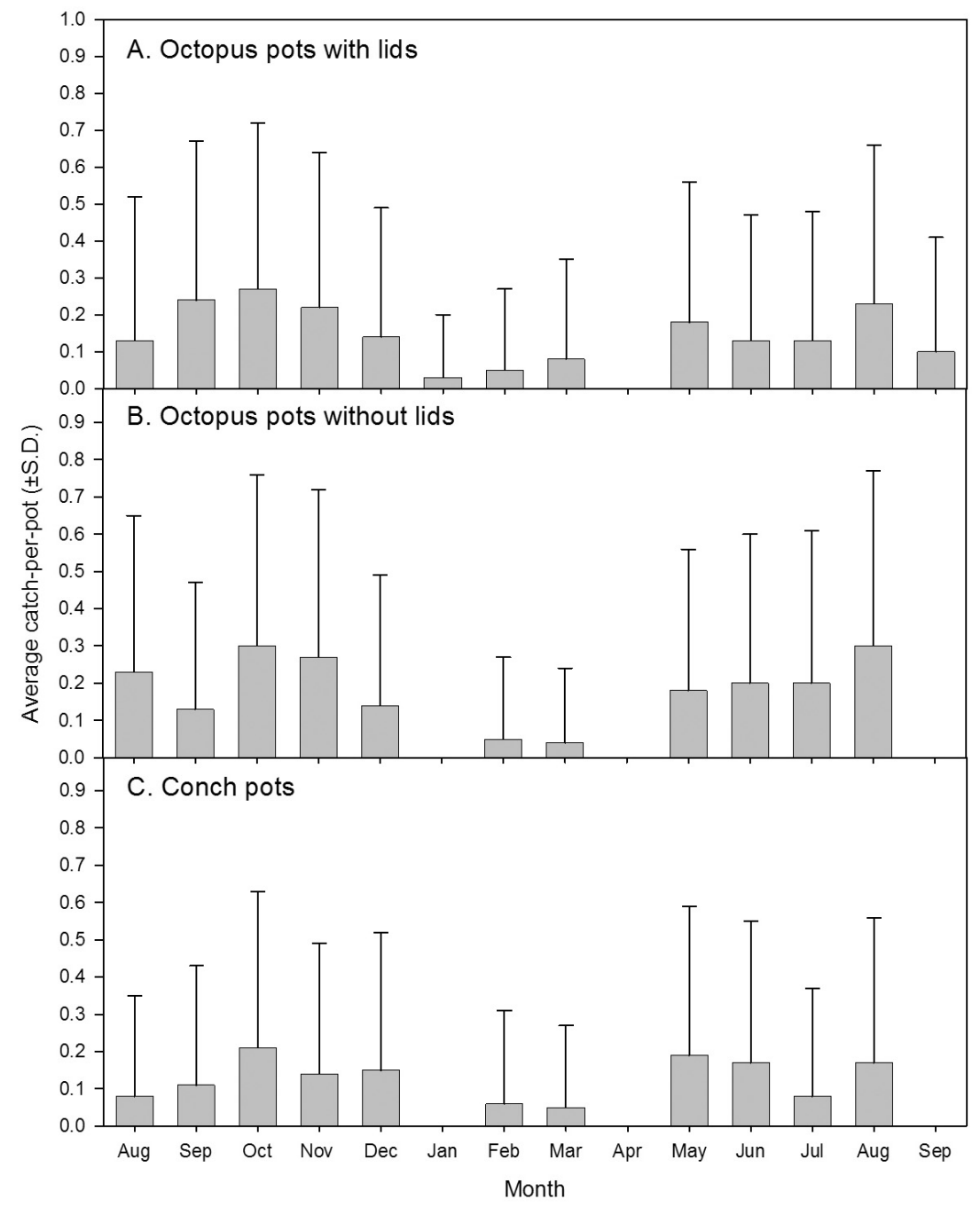

Figure 4.-Average catch-per-pot of octopi $( \pm$ S.D. $)$ captured by octopus pots with lids (A), octopus pots without lids (B), and conch pots (C), by month, from August 2010 through September 2011 for experimental gear fished in Onslow Bay, N.C. No bar for a month-gear combination represents no catch of octopi.

(location of the reef), pot type (conch, octopus without lid, and octopus with lid), relief type (none (sand), low, medium, or high), and soak time (days). There were 19 different soak times in this study; soak time was considered a categorical variable because of the discrete nature of these data.

An information-theoretic perspective was used to compare the fits of relatively simple GLM's to help determine those combinations of gear and environmental factors most influential on occupancy of pots by octopi. Models were constructed that contained some or all of the main effects and any logical first-order interactions. A model with three-way interactions also included two-way sub-interactions.

Second-order Akaike's Information Criterion (AICc: Burnham and Anderson, 2002) was calculated for each model. AICc was computed instead of AIC due to potential over-dispersion of the data used as the response variable (Burnham and Anderson, 2002). 
The $\mathrm{AICc}_{i}$ value obtained from each model was then used to compare fits among all models to determine the combination of predictors that best explained variation about the catch data. The $\triangle \mathrm{AICc}$ value for each model was calculated as the difference between the value of any particular model $\left(\mathrm{AICc}_{i}\right)$ and the minimum $\mathrm{AICc}$ for the best fitting model in the set $\left(\mathrm{AICc}_{\text {min }}\right)$. The model with the $\mathrm{AICc}_{\text {min }}$ value was considered to be the one representing the data adequately with the fewest number of parameters; however, models that differed by $<\sim 4 \Delta$ AICc were all regarded as having reasonable support (Burnham and Anderson, 2002). Akaike weights $\left(w_{i}\right)$ of each model were computed to help gauge the relative support for each model in the set; the value of $w_{i}$ varies between 0 and 1 , with the greatest value for a model set indicating that a particular model best fits the data. Burnham and Anderson (2002) provide equations used to compute AICc and $w_{i}$.

\section{Results}

\section{Environmental Ranges and Catch by Pot Type}

SST's on sampling trips ranged from a low of $8.3^{\circ} \mathrm{C}$ (Jan. 2011) to a high of $28.2^{\circ} \mathrm{C}$ (Aug. 2011). Four strings set over hard bottom were lost in the first four months of fishing; each lost string was set over medium or high relief. The only string set over hard bottom that was not lost was consistently set over low relief.

A total of 625 pots with lids, 625 pots without lids, and 250 conch pots were fished during the study; all pots

\begin{tabular}{|c|c|c|c|}
\hline $\begin{array}{l}\text { Bottom } \\
\text { type }\end{array}$ & Pot type & $\begin{array}{l}\text { No. of } \\
\text { pots }\end{array}$ & Mean \pm S.D. \\
\hline \multirow[t]{3}{*}{ Hard } & Octopus pots with lids & 185 & $0.168 \pm 0.374$ \\
\hline & Octopus pots without lids & 185 & $0.178 \pm 0.384$ \\
\hline & Conch pots & 73 & $0.110 \pm 0.315$ \\
\hline \multirow[t]{3}{*}{ Sand } & Octopus pots with lids & 440 & $0.143 \pm 0.351$ \\
\hline & Octopus pots without lids & 440 & $0.173 \pm 0.396$ \\
\hline & Conch pots & 177 & $0.113 \pm 0.317$ \\
\hline
\end{tabular}

combined caught a total of 229 octopi. The greatest mean catch pot type occurred in spring and summer months (Fig. 4). Mean catch rates were 0.150 \pm 0.392 ( \pm S.D.) for octopus pots with lids, $0.174 \pm 0.319$ for octopus pots without lids, and $0.112 \pm 0.358$ for conch pots.

Mean mass of octopi varied little among pot types: $0.53 \pm 0.28 \mathrm{~kg}$ for octopus pots with lids, $0.57 \pm 0.28 \mathrm{~kg}$ for pots without lids, and $0.54 \pm 0.23$ $\mathrm{kg}$ for conch pots. Mean catch rates by each trap type varied little between hard and sandy bottom (Table 1) but did vary among stations. Across all pot types, catch rates were $0.149 \pm$ 0.356 at Little Ten, $0.101 \pm 0.301$ at Northwest Places, $0.203 \pm 0.403$ at 195 Rock, $0.144 \pm 0.352$ at 14.9 Rock, and $0.134 \pm 0.341$ at Southeast Bottom. Mass of individual octopus was positively correlated with water temperature $(p=0.006)$ but with little variation about this relationship being explained (Pearson correlation coefficient $r=0.089$ ).

The predictive relationship between proportional occupancy of traps by octopi $(\mathrm{CATCH})$ and soak times (TIME) was significantly negative. This relationship was described by the equation:

$$
\begin{gathered}
\text { CATCH }=\exp (-1.212 \\
-0.032 * \text { TIME }) / \\
(1+\exp (-1.212-0.032 * \text { TIME })) .
\end{gathered}
$$

The probability levels for the coefficients of the intercept $(a)$ and slope (b) of the fitted line were $<0.001$ and 0.001 , respectively. Predicted catch rates declined with greater soak times (Fig. 5). Thus, gear saturation was not

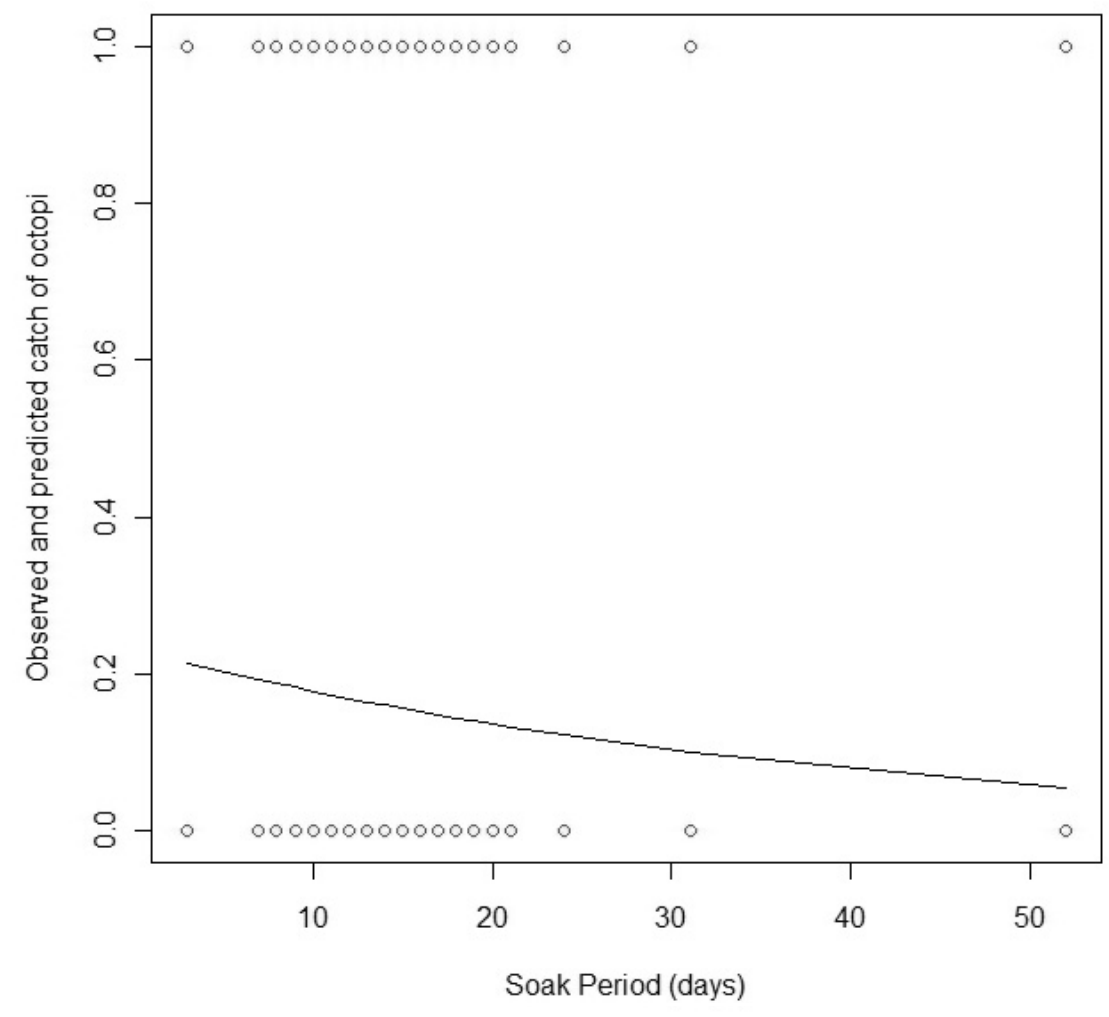

Figure 5.-Observed catch (points) and predicted catch (line) of octopi (across all pots types) vs. soak time (days) for experimental pots fished in Onslow Bay, N.C., from August 2010 through September 2011. Predicted catch (CATCH) with soak time (TIME) (days) was determined via a logistic model, where $\mathrm{CATCH}=$ $\exp (-1.212-0.032 *$ TIME $) /(1+\exp (-1.212-0.032 *$ TIME $))$. 
Table 2.-Candidate models fitted to octopus catch data from fishing unbaited octopus and conch pots in Onslow Bay, N.C., between August 2010 and September 2011. Second-order Akaike Information Criterion (AICc) was used to evaluate model performance, with the lowest value indicating the most parsimonious model. Categorical predictor variables incorporated into modeling included pot type (pot), station, soak time (time), and bottom type (relief). Sea surface water temperature (SST) $\left({ }^{\circ} \mathrm{C}\right.$ ) was incorporated into modeling as a continuous predictor typer The base model did not include any predictor variables (intercept only). Models with first-order interactions had individual interactive factors incorporated into the model as main effects.

\begin{tabular}{lrccc}
\hline Model & $k$ & AICc & $\Delta$ AICc & $w_{i}$ \\
\hline base + SST + station + time + SST*time & 35 & 1223.1 & 0 & 1.0 \\
base + SST + time + SST*time & 32 & 1231.3 & 8.2 & 0.0 \\
base + SST + time + station & 25 & 1237.8 & 14.7 & 0.0 \\
base + relief + SST + relief*SST & 9 & 1247.5 & 24.4 & 0.0 \\
base + station +temp & 7 & 1250.7 & 27.6 & 0.0 \\
base + SST + time & 21 & 1256.1 & 33.0 & 0.0 \\
base + SST & 3 & 1258.9 & 35.8 & 0.0 \\
base + time & 20 & 1270.7 & 47.6 & 0.0 \\
base + station & 6 & 1278.2 & 55.1 & 0.0 \\
base + station + relief + station*relief & 12 & 1278.7 & 55.6 & 0.0 \\
base + relief & 5 & 1279.7 & 56.6 & 0.0 \\
base + station + relief & 9 & 1280.1 & 57.0 & 0.0 \\
base + pot & 4 & 1282.8 & 59.7 & 0.0 \\
base & 2 & 1283.9 & 60.8 & 0.0
\end{tabular}

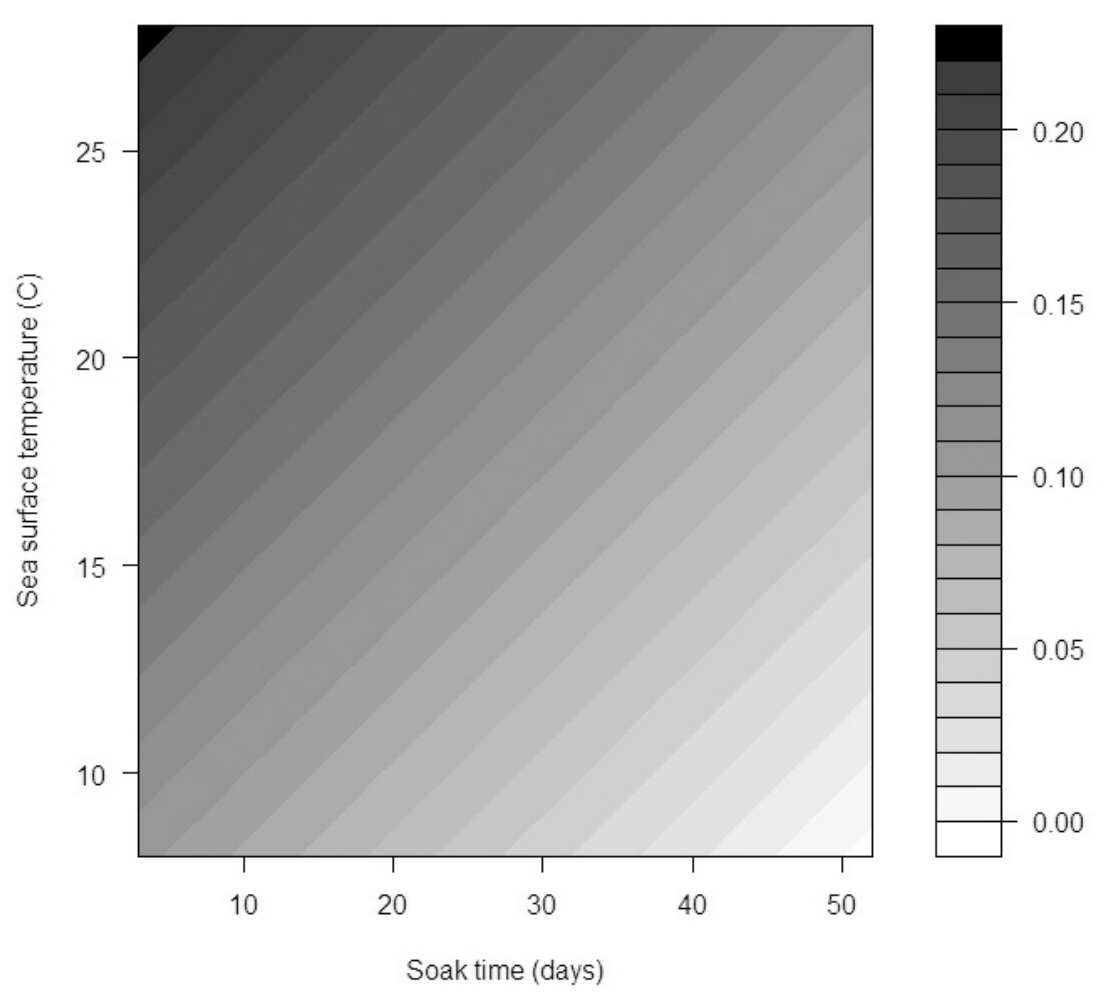

Figure 6.-Predicted proportional catch of octopi (across all pots types) (gray scale) vs. soak time (days) (x axis) and sea surface water temperature (SST) $\left({ }^{\circ} \mathrm{C}\right)$ (y axis) for experimental pots fished in Onslow Bay, N.C., from August 2010 to September 2011. Predicted catches of octopi for the figure were determined via a generalized linear model that explained proportional catch as a function of soak time, SST, station, and the interaction between soak time and SST; station is not graphed. Values plotted on the $\mathrm{x}$ and $\mathrm{y}$ axes range over the values of soak time and SST from field data. an issue in considering soak time as a factor in modeling catch data with GLM's. For this reason, modeling of catch rates (below) considered all soak times simultaneously without binning them.

The GLM that best fit catch data explained proportional catch as a function of SST, soak time, station, and an interaction between SST and soak time. This model received sole support from the data (Table 2). Greatest catches were predicted to occur over warmer temperatures and shorter soak times (Fig. 6). Pot type and relief type were not important explanatory variables in predicting proportional catch.

\section{Discussion}

\section{Catch Patterns}

Proportional catch varied with sea surface temperature (SST), soak time, and the station where the gear was deployed (most parsimonious model fit, Table 2). Commercial fishermen interested in targeting octopus should consider these factors in determining the best times of year to fish, optimal durations over which to set their gear, and where to fish. Stations with the greatest mean catch in this study are regarded as more unknown and difficult to locate; as a result, they may experience less intense harvest pressure by fisheries that interact with octopi (such as Black Sea Bass trapping and scuba diving). In contrast, Northwest Places is a prominent ledge easily identified by fishermen; this station had the lowest catch rates. Another prominent ledge, Little Ten, had a mean catch rate between stations with the lowest mean catch rate (Northwest Places) and the highest (195 Rock).

Increasingly greater soak times negatively affected catch rates. This is a counter-intuitive result that differs from the study by Whitaker et al. (1991) and may reflect the action of the gear when it was soaking over longer periods. Whitaker et al. (1991) fished a pot type constructed from two $10 \mathrm{~cm}$ (diameter) PVC tubes placed side-by-side and found that catch rates with this pot type increased with soak 
time. In that study, pots were saturated after 48-day soak times, catches began to asymptote after soak times of roughly 6-10 days, and the catch rate was 0.329 . Single-tube pots also made of $10 \mathrm{~cm}$ diameter plastic drain pipe (similar to ours) had a mean catch rate of 0.273 in the Whitaker et al. (1991) study. Our single-tubed pots had a catch rate roughly half of Whitaker et al. (1991). In addition to gear differences, the discrepancy in catch rates between the two studies could be due to differences in fishing sites, bottom types, or latitudinal or decadal trends in abundance.

It is likely that octopus pots used in this study rolled on the bottom, with the severity of rolling increasing with longer soak times and a correspondingly higher likelihood of sea swell moving the gear. The mud fouling observed in pots with longer soak time supports my belief that pots rolling on the bottom negatively affected catch rates as soak times increased. Potential solutions to prevent pots from rolling on the bottom would include fishing two pots side-by-side (Whitaker et al., 1991) or skewering each pot with a piece of rebar. Each of these gear designs require additional expense and considerations on how they could most easily be fished as strings without getting them tangled with the warp line or snood lines. In contrast, the gear modification of adding lids to the plastic pots to retain octopi during haulback seems unnecessary; pot type was not an important factor in model fitting to catch data. Many octopi were so embedded in the plastic pots that they needed to be soaked in ice water to elicit egress.

Temperature also influenced catch rates, with the greatest catches occurring over the highest SST's. There are at least two potential explanations for the positive relationship between catch rates and temperature. The first is that octopi are more active at warmer temperatures; Whitaker et al. (1991) similarly found a positive relationship between water temperature and catch rate. The optimal temperature for growth of this species is $17.5^{\circ} \mathrm{C}$ (Gi- ménez and García, 2002). If warmer spring and summer temperatures off the coast of North Carolina yield the greatest catch rates, gear would have to be moved to warmer waters further offshore in the winter to maximize catch rates during colder periods; the five sites visited in this study are not far enough offshore to be influenced by warmer Gulf Stream waters during the winter.

The second explanation for the positive relationship between catch rates and temperature is that individuals recruiting to the gear are more abundant during warmer seasons due to the reproductive cycle of this species. Whitaker et al. (1991) believed that the peak reproductive activity of octopi off the coast of South Carolina occurred in the spring. A spring spawning period has been found for octopi caught in the Northeast Atlantic (Otero et al., 2007). This seasonal spawning peak coincides with the highest catches in summer months; many octopi were likely age-0 individuals newly recruited to the gear used in this study.

The station where the gear was set was the final factor that influenced catch rates in the best fitting GLM. Differences in catches between stations could be a consequence of different levels of fishing effort. Another explanation for this result is that migrating octopi moving into an area of limestone bottom found the habitat furnished by pots to be more attractive where there is less naturally occurring bottom habitat. There is also a chance that differences in proportional catch rates between stations reflect the ability of the fisherman to relocate and set gear in the proximity of some stations more efficiently than others.

Finally, stations with the greatest catch rates are more difficult to find and may experience lower pressure by fisheries that collect octopi as bycatch. Of the five stations where gear was set, 195 Rock, 14.9 Rock, and Southeast Bottom are not as well known as the other two sites and had equal or greater catch rates. Experienced commercial operators may find productive fishing opportunities in other cryptic hard bottom areas off the North Carolina coast that were not visited during this study.

Bottom relief was thought to be another important variable in dictating catch patterns. However, the loss of several strings of gear over hard bottom relatively early in the sampling year may have hindered the ability to effectively determine the relative influence of hard vs. sand bottom on catch.

\section{Gear and Logistical Considerations}

In designing this study there was a concern that minor movement (rolling) of pots over sand bottom would deter octopi from entering them and that large movement of entire strings would lead to high rates of gear loss unless it was effectively anchored with weights. Conch pots anchored strings to the bottom and eliminated the loss of any string set on sand over the duration of this study. Fishing over sand in the vicinity of hard reef structure appears to offer the greatest potential for relatively high catch rates and minimum loss rates. Strings set over hard bottom were lost due to pots getting caught in the bottom itself rather than being transported by wave action to other areas. The distance and frequency of dispersion of octopus away from natural hard bottom habitat and onto sand bottom remains unclear; knowing these movement patterns could have ramifications for where fishermen could set their gear to maximize catch rates while minimizing gear loss. Loss of this mostly synthetic fishing gear at the rates experienced in this study would be a financial and environmental consideration if this fishery expanded in this region.

Pots were set on a number of live bottom and nearby sandy bottom sites roughly 10-20 nmi offshore. However, gear conflicts with other boaters and fisheries (such as the shrimp trawl and recreational fisheries) may have resulted in boat-related gear loss in these more heavily used nearshore waters.

\section{Financial Considerations}

A targeted commercial fishing operation for this species is not viable 
unless catch rates can be increased and gear loss decreased. While catch rates may be increased with further modifications to gear designs and fishing tactics, the abundance of this species does not appear sufficient to support a directed commercial operation for it. Each trip lasted roughly $10 \mathrm{~h}$ and required approximately 400 liters of fuel (at $\sim \$ 3.786 /$ gallon $(\$ 1.00 /$ liter $)$ ). Octopus prices in 2012 were roughly $\$ 2.20$ per $\mathrm{kg}$ ex-vessel, $\$ 6.60$ per $\mathrm{kg}$ wholesale, and $\$ 13.20$ per $\mathrm{kg}$ retail. At these respective prices, a small-boat operation, such as the one used for these research trips, would need to land at least 160, 68, and $34 \mathrm{~kg}$ of octopi per day trip to remain profitable.

\section{Bycatch Considerations}

Potting for octopus represents a "clean" fishery. Fishes by-caught in this study, mainly consisting of small sea basses, Centropristis spp., were released alive and in good condition (swam down). Only one octopus in the study was caught dead. Thus, discard mortality of both the target and bycatch species in this fishery, at least over the depths fished in this study, is negligible. Lost gear does not retain fishes or invertebrates, as they can readily egress at will. Instead of the PVC used in this study, pots made from natural material such as clay (Rathjen, 1991) may further reduce the environmental impact of this fishery, especially given the amount of gear that can be lost over "live-bottom." Because of the simple design, cost-effectiveness, and low impact of the gear, as well as low catch rates of the target species, fishing for octopi may most appropriately be considered a secondary option for fishermen that target other demersal species off of North Carolina.

\section{Acknowledgments}

This study was funded by the North Carolina Sea Grant Fishery Resource Grant Program, Project 10-FEG-07. The comments provided by three anonymous reviewers substantially improved the manuscript.

\section{Literature Cited}

Burnham, K. P., and D. R. Anderson. 2002. Model selection and inference: a practical information-theoretic approach, second ed., Springer-Verlag, N.Y., 488 p.

Giménez, F. A., and B. G. García. 2002. Growth and food intake models in Octopus vulgaris Cuvier (1797): influence of body weight, temperature, sex and diet. Aqua. Int. 10(5): 361-377.

MacIntyre, I. G., and J. D. Milliman. 1970. Physiographic features on the outer shelf and upper slope, Atlantic Continental Margin, southeastern United States. Geol. Soc. Am. Bull. 81: 2577-2598.

Otero, J., A. F. González, M. P. Sieiro, and Á. Guerra. 2007. Reproductive cycle and energy allocation of Octopus vulgaris in Galician waters, NE Atlantic. Fish. Res. 85(1-2):122-129.

Rathjen, W. F. 1991. Cephalopod capture methods: an overview. Bull. Mar. Sci. 49(1-2):494-505.

Voss, G. L., L. Opresko, and R. Thomas. 1973. The potentially commercial species of octopus and squid of Florida, the Gulf of Mexico and the Caribbean area. Univ. Miami, Sea Grant Field Guide Ser. 2, 33 p.

Whitaker, J. D., L. B. Delaney, and J. J. Jenkins. 1991. Aspects of the biology and fishery potential for Octopus vulgaris off the coast of South Carolina. Bull. Mar. Sci. 49(1-2): 482-493. 